\title{
Revitalização para quem? Política urbana e gentrificação no Centro de Santos
}

\author{
Revitalization to whom? Urban policy \\ and gentrification in Downtown Santos
}

André da Rocha Santos

\section{Resumo}

0 artigo aborda, a partir do conceito de gentrificação de Neil Smith, o processo de enobrecimento do território santista e de revitalização do Centro Histórico que vem ocorrendo no município desde meados da década de 1990. A partir da análise de quatro administrações municipais - 19972000; 2001-2004 do PPB e 2005-2008; 20092012 do PMDB - e suas respectivas políticas de planejamento urbano, é interpretado como visões pró-mercado, referente à temática urbana, têm influenciado na elitização do município e na gentrificação da área central, somado-se à falta de uma política de inclusão social dos moradores de cortiços e habitações precárias.

Palavras-chave: gentrificação; revitalização; administrações municipais; inclusão social; Santos/SP.

\begin{abstract}
The article discusses, based on Neil Smith's concept of gentrification, the process of ennoblement of the city of Santos and of revitalization of the historic center, which has been occurring in the city since the mid-1990s. From the analysis of four municipal administrations - 1997-2000; 2001-2004 (political party: PPB); and 2005-2008; 2009-2012 (political party: PMDB) - and their urban planning policies, we interpret how promarket views concerning the urban theme have influenced the gentrification of the city and the gentrification of the downtown area, added to the lack of a policy of social inclusion of residents of slums and substandard housing.
\end{abstract}

Keywords: gentrification; revitalization; municipal administrations; social inclusion; Santos/SP. 


\section{Introdução}

0 termo gentrification deriva de gentry que, por sua vez, deriva do francês arcaico genterise que significa "de origem gentil, nobre". Desta feita, entende-se também a reestruturação de espaços urbanos residenciais e de comércio independentes com novos empreendimentos prediais e de grande comércio, ou seja, causando a substituição de pequenas lojas e antigas residências. Nas últimas décadas, esse fenômeno tem, por exemplo, ocasionado a mudança radical da natureza das lojas de Queen St. West em Toronto no Canadá ou o enobrecimento de vários bairros antes populares de São Francisco nos Estados Unidos. 0 fenômeno afeta uma região ou bairro pela alteração das dinâmicas da composição do local, tal como novos pontos comerciais ou construção de novos edifícios, valorizando a região e afetando a população de baixa renda local. Tal valorização é seguida de um aumento de custos de bens e serviços, dificultando a permanência de antigos moradores de renda insuficiente para sua manutenção no local cuja realidade foi alterada.

Apesar de a expressão inglesa gentrification ter sido usada pela primeira vez pela socióloga britânica Ruth Glass, em 1964, ao analisar as transformações imobiliárias em determinados distritos londrinos, apenas com o geógrafo britânico Neil Smith o processo foi analisado em profundidade e consolidado como fenômeno social presente em diversas cidades contemporâneas. Smith identificou os vários processos de gentrificação em curso nas décadas de 1980 e 1990 e tentou sistematizá-los, especialmente os ocorridos em Nova York. Esse processo nos bairros populares e/ou degradados pode tornar-se um problema social de sérias consequências quando a oferta de moradia a preços menores é inexistente (Smith, 2006).

Corroborando visões como a de BoteIho (2005) que destaca a disseminação de experiências de revitalização no Brasil e sua relação com o processo de gentrificação - sendo as cidades de Salvador, Recife, São Paulo e Rio de Janeiro as principais vitrines -, esse autor apresenta outros casos de intervenção nas regiões centrais em municípios menos estudados como Vitória, Fortaleza e São Luís. Questionando se revitalização virou sinônimo de gentrificação e qual o papel da cultura como elemento diferenciador, contribui na constituição de uma análise desses processos nas grandes cidades brasileiras ressaltando a distinção entre os procedimentos adotados nos Estados Unidos e no Brasil, em que "o principal elemento diferenciador diz respeito ao papel do poder público como condutor dos processos de revitalização" (p. 56).

Nesse sentido, nas últimas décadas, algumas cidades brasileiras marcadas pelo declínio de certas áreas têm apresentado diversas ações do poder público voltado para se reverter tal situação. Em épocas de crise ou instabilidade em que o mercado e suas forças sociais não conseguem dar conta de uma determinada situação social, o Estado é chamado a intervir ou assumir a direção de atividades que se haviam preservado no nível do mercado. Quando as forças produtivas e as relações de apropriação ou produção entram em dissonância, o Estado ganha novas tarefas e se impõe em outras esferas da vida econômica e social. Para controlar e reorientar as manifestações inesperadas da realidade, surge de maneira mais visível e ampla em épocas críticas (lanni, 2004). 
Segundo Castells (1982):

[...] o Estado não é um agente neutro; nem tampouco o instrumento de uma minoria oligárquica como certas visões esquemáticas, às vezes, tratam de assinalar. A intervenção do Estado é uma intervenção complexa, determinada no plano do urbanismo, em primeiro lugar, pelos conflitos políticos e sociais subjacentes à ação pública, quer dizer, pelo enfrentamento no seio do Estado e com relação ao Estado de grupos sociais e de grupos de interesse. (Castells, 1982, p. 69)

As décadas de 1970 e 1980 marcaram a época de crise da ideia de plano ou de planejamento no sentido modernista. Por oposição à prática do planejamento urbano, as práticas pós-modernistas passaram a se pautar por projetos urbanos, abandonando a visão do espaço como algo a ser moldado para propósitos sociais, ou seja, sempre subordinadas a um projeto abrangente e macroestrutural e passando a ver as intervenções nos espaços urbanos mais parciais ou pontuais, como coisa "independente e autônoma a ser moldada segundo objetivos e princípios estéticos que não têm necessariamente nenhuma relação com algum objetivo social abrangente (...)" (Harvey, 1992, p. 69).

Esse processo ocasionou várias mudanças em muitas cidades que, diante de inúmeros fatores como a desindustrialização, o enxugamento da produção e precarização do trabalho (com declínio das profissões formais, aumento da subcontratação e do desemprego estrutural), a perda da capacidade de investimentos do setor público e o aumento do setor de serviços, financeiro, de consumo e de entretenimento, vêm induzindo a certa mudança de visão nas práticas tradicionais, não só do Estado, mas de outros agentes interventores sobre o espaço urbano. Surgiu, assim, um novo momento no processo de intervenção urbana. Por serem ações voltadas a tecidos urbanos já existentes, no sentido de adequá-los outra vez, ou readaptá-los, essas realizações vêm recebendo, a cada novo contexto, novas denominações, geralmente com o prefixo re, como, por exemplo, revitalização, requalificação ou revalorização (Vasconcellos e Mello, 2006).

Segundo Harvey (1992) e Smith (2006; 2007), esse período foi o reflexo de um novo modelo de produção, ou seja, o intervalo de tempo em que ocorreu a transição do regime de acumulação de capital fordista-keynesiano para um regime de acumulação flexível. Em certos projetos de renovação urbana, as intervenções significaram uma perspectiva de atuação que passou a atender demandas de grupos de maior poder aquisitivo, ou o poder do mercado, contribuindo, muitas vezes, para uma elitização do contexto urbano da área central. Desse processo decorreu que, sobretudo em certas cidades, áreas foram revitalizadas e passaram a ser utilizadas por grupos sociais de maior renda, com tendência à criação de determinados atritos e à expulsão dos usuários originais de baixa renda ou de origem étnica distinta daquela dos novos consumidores.

Em certos casos, articularam-se intervenções urbanas de caráter mais pontual, justificadas ideologicamente pelas mudanças de ajuste urbano à globalização, muito marcadas pelas alianças entre interesses do capital e do poder público. Isso resultou em processos marcados por práticas excludentes, já que essas intervenções estão norteadas pelo mercado, tendo como público preferencial as classes médias e altas (Frúgoli Júnior, 2000; Nobre, 2003; Vainer, 2000). Desse modo, torna-se de suma 
importância atentar para a crítica a esse tipo de ação que, em certos casos, acabam introduzindo mudanças ou intervenções que terminam por favorecer o uso de determinados espaços apenas por grupos sociais mais privilegiados, criando, assim, uma espécie de "gentrificação cultural" levando consigo o processo de "gentrificação urbana". Segundo Smith (2007):

Na mídia, a gentrificação tem sido apresentada como o maior símbolo do amplo processo de renovação urbana que vem ocorrendo. Sua importância simbólica ultrapassa em muito sua importância real; é uma pequena parte, embora muito visível, de um processo muito mais amplo. 0 verdadeiro processo de gentrificação presta-se a tal abuso cultural da mesma forma que ocorreu com a fronteira original. Quaisquer que sejam as reais forças econômicas, sociais e políticas que pavimentam o caminho para a gentrificação, e quaisquer que sejam os bancos e imobiliárias, governos e empreiteiros que estão por trás do processo, o fato é que a gentrificação aparece, à primeira vista, $\mathrm{e}$ especialmente nos EUA, como um maravilhoso testemunho dos valores do individualismo, da família, da oportunidade econômica e da dignidade do trabalho (o ganho pelo suor). Aparentemente, ao menos, a gentrificação pode ser tocada de forma a executar alguns dos acordes mais ressonantes de nosso piano ideológico. (p. 18)

Arantes (2000) também analisou de forma esclarecedora o processo de gentrificação:

Associados aos políticos, ao grande capital e aos promotores culturais, os planejadores urbanos, agora planejadores-empreendedores, tornaram-se peças-chave dessa dinâmica. Esse modelo de mão única, que passa invariavelmente pela gentrificação de áreas urbanas "degradadas" para torná-las novamente atraentes ao grande capital através de mega-equipamentos culturais, tem dupla origem, americana (Nova-York) e européia (a Paris do Beaubourg), atingindo seu ápice de popularidade e marketing em Barcelona, e difundindo-se pela Europa nas experiências de Bilbao, Lisboa e Berlim. (p. 31)

Vainer (2000), numa posição desfavorável à elitização de certas áreas da cidade, aponta essa tendência como a venda daqueles atributos específicos que constituem insumos valorizados pelo capital transnacional. Segundo o autor, a ideia da cidade como uma mercadoria (de luxo) a ser vendida num mercado extremamente competitivo - em que outras cidades também estão à venda - é uma das ideias mais populares entre os projetos atuais de renovação urbana de áreas centrais da cidade.

Assim, a discussão em torno de políticas públicas, visando à revitalização de áreas urbanas que se encontram em processo de deterioração, passou a representar uma resposta possível à crise instaurada. A partir de determinado momento, grandes investimentos em megaprojetos, que até recentemente estavam concentrados em áreas periféricas ou em áreas de expansão imobiliária, passaram a dirigir seus esforços e atenções para áreas situadas em pontos centrais, históricos e de grande valor simbólicos nas cidades.

A intenção, portanto, é averiguar, para 0 caso de Santos, quais foram e como se organizaram as principais intervenções e projetos no processo de revitalização a partir da política urbana implantada pelas administrações municipais/poder público na estruturação dos equipamentos urbanos. Pretende-se também 
analisar quais concepções têm norteado tais intervenções, levando-se em conta o planejamento urbanístico da área central nas recentes e diferentes gestões.

\section{A implantação da visão pró-mercado em Santos}

Após duas administrações do Partido dos Trabalhadores (PT), a partir de 1997 o município de Santos passou a ser administrado por um partido em oposição a esses governos - o Partido Progressista Brasileiro (PPB) - de posicionamento por medidas pró-mercado e de predomínio do crescimento econômico em detrimento a políticas de distribuição e inclusão social (Mainwaring, Meneguello e Power, 2000). 0 PPB pode ser considerado um dos partidos mais antigos do sistema partidário brasileiro, tendo suas origens em 1966 no bipartidarismo do regime militar, sob a denominação de Arena.

Com o processo de redemocratização e o restabelecimento do multipartidarismo, em 1979, a agremiação passou a se chamar PDS. Entre os anos de 1980 e 1990, seu principal líder, Paulo Maluf, disputou importantes eleições como a Presidência da República, em 1985, - de forma indireta - o governo do Estado, em 1986; a prefeitura paulistana, em 1988; novamente a presidência da República, em 1989; outra vez o governo paulista em 1990; e, mais uma vez, a prefeitura, em 1992, todas com o mesmo candidato que ganhou apenas essa última, no segundo turno (Pierucci e Lima, 1991; 1993).

Como a emenda da reeleição ainda não havia sido aprovada nas eleições municipais de 1996, Maluf empenhou-se em transferir seus votos na capital paulista para o candidato Celso Pitta, seu ex-secretário de finanças. Além da vitória em São Paulo, o partido saiu fortalecido pelo bom desempenho nacional, ampliando o número de prefeitos e vereadores. Em Santos, com PT e PPB polarizando o segundo turno, 0 deputado federal Beto Mansur derrotou a candidata e ex-prefeita Telma de Souza por uma pequena margem de votos (Carvalho, 1999; Seade, 2013).

Desde a campanha eleitoral, Mansur soube aproveitar o bom momento do partido na campanha municipal de 1996 e consolidou o discurso anti-petista de crítica ao autoritarismo e uso da máquina pública da prefeitura em benefício do partido. 0 então candidato do PPB atrelou seu nome ao de Maluf buscando beneficiar-se dos seus $62 \%$ de aprovação ao fim de mandato na capital (Almeida, 2004) e procurando imprimir a imagem de empreendedor e "tocador de obras", inclusive propondo para Santos o programa conhecido como Cingapura de prédios de apartamentos como solução para o problema habitacional para as camadas de baixa renda. ${ }^{1}$ Com o apoio formal do PMDB no segundo turno e de setores insatisfeitos com a possível permanência do PT, beneficiou-se da imagem atribuída por parte da imprensa ao petismo, ligado à desordem e de pessoas vindas de outros municípios para governar. Como solução propôs uma gestão técnica e de eficiência administrativa, com profissionais do próprio município.

Com o início da administração (19972000), numa simbólica demonstração de interrupção em relação ao governo anterior, foi retirado o projeto de lei 50/95 que instituiria o novo plano diretor para ser rediscutido. Nas discussões envolvendo a política de 
planejamento urbano, o debate acerca do mercado imobiliário e a vinda de grandes construtoras e incorporadoras voltaram a ganhar relevância, especialmente seus índices urbanísticos e a não limitação do número máximo de pavimentos admitidos para os edifícios. Desde o início o governo dispôs de maioria na Câmara Municipal, a qual conseguiu fazer crescer no decorrer do mandato. Nos novos debates buscou promover melhor diálogo com os setores produtores urbanos e outros considerados estratégicos pelo governo. No novo modelo de planejamento que se buscava implantar, a gestão empresarial ganhou características específicas, com maior ênfase ao empreendedorismo, à competitividade e à busca por resultados (Nunes, 2005).

Após quase dois anos de discussão, em novembro de 1998 foram aprovados, na mesma sessão legislativa, o novo Plano Diretor de Desenvolvimento e Expansão Urbana e a Lei de Disciplinamento e Ordenamento do Uso e Ocupação do Solo da Área Insular (PMS, 1998a; PMS, 1998b). Em relação aos principais instrumentos legais que alteraram o zoneamento da lei de uso e ocupação, Carriço (2006) apontou como o coeficiente de aproveitamento dos lotes foi progressivamente ampliado, alcançando na prática cerca de nove vezes a área do lote nas áreas onde 0 mercado imobiliário era mais ativo. As modificações alteraram profundamente os padrões urbanísticos, reforçando o processo de verticalização e valorização imobiliária.

0 aumento do aproveitamento não se restringiu à orla, possibilitando verticalizar também as áreas antes desprezadas pelo mercado. Ainda segundo o autor, nos anos posteriores, 0 setor teve grande crescimento usufruindo do aumento do potencial construtivo possibilitado pela nova norma direcionando-se, sobretudo, ao lançamento de empreendimentos voltados às camadas de alta renda gerando, como uma de suas consequências, o reforço ao processo de expulsão da população de menor renda e ampliando a migração inter-regional em função da elevação marcante do valor imobiliário (Carriço, 2006).

0 plano diretor e a lei de uso e ocupação foram denominadas por Souza (2006) como uma "flexibilização do aparato legal" na forma de captar mais recursos, viabilizar projetos e institucionalizar formas de parceria entre os setores público e privado na elaboração e execução de projetos. As legislações consideraram também a valorização da área central como estratégica para o desenvolvimento concentrando as discussões apenas em seus aspectos "culturais", deixando de lado outras questões como redução das desigualdades e habitação, por exemplo. Para tanto, estabeleceu no novo zoneamento o perímetro das Áreas de Proteção Cultural (APC) contendo os Corredores de Proteção Cultural (CPC) como "áreas de interesse cultural com acervo de bens imóveis que se pretende proteger, ampliando os incentivos à recuperação e preservação, pelo instrumento de transferência do potencial construtivo"2 (Souza, 2006, p. 115).

Após a aprovação das leis, as discussões envolvendo a requalificação urbana da área central se deram particularmente no âmbito das Secretarias de Turismo (Setur) que, inclusive, produziu em 1999 o documento Integra Centro expondo o panorama das ações e intervenções realizadas pela gestão. 0 documento vislumbrou ainda o primeiro esboço com as intenções da prefeitura de empreender um 
programa mais amplo de revitalização, buscando conter as críticas dos proprietários de imóveis que reivindicavam maiores incentivos por parte da administração à restauração das construções antigas.

Em paralelo foram realizadas intervenções pontuais que atenderam a antigas reivindicações por meio de recursos provenientes do governo do estado através do Departamento de Apoio ao Desenvolvimento das Estâncias (Dade) e do Fundo de Desenvolvimento Metropolitano da Baixada Santista (Fundesb). ${ }^{3}$ Após a conclusão das restaurações da Prefeitura Municipal, na Praça Mauá, da Bolsa Oficial do Café e da Câmara Municipal, tiveram início as discussões relativas à reforma da Rua XV de Novembro para implantação de fiação elétrica subterrânea, calçadas de ladrilho e postes de ferro fundido. Esses e outros projetos como a intenção de restauro da estação ferroviária para transformar num museu ferroviário que também serviria como palco de eventos, assim como as obras do Teatro Coliseu, e outros, suscitaram a ampliação do debate na imprensa e nos meios de comunicação.

A sanção do projeto de lei 1891/2000 instituindo o "Dia do Centro" todo dia 16 de agosto procurou melhor interlocução e apoio das entidades comerciais. Contudo, a maior promessa dentre os projetos de revitalização foi o anúncio da volta dos bondes extintos desde 1971. A linha turística projetada tinha a previsão de quatro paradas - Praça Mauá, Rua do Comércio, estação do Valongo e Praça Barão do Rio Branco - com quase dois quilômetros de extensão.

Figura 1 - Bonde turístico inaugurado em 2000 (Alegra Centro, 2013)

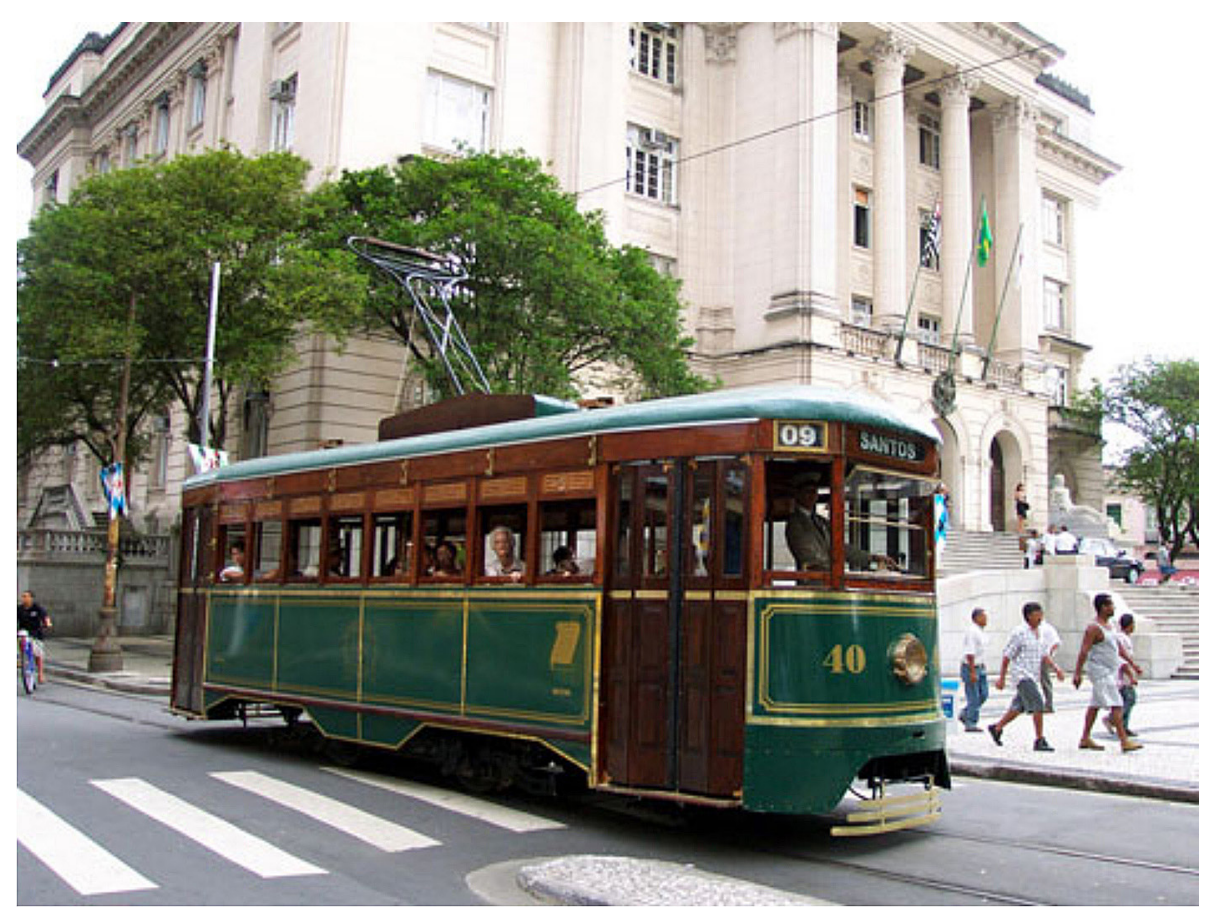


Nas eleições municipais de 2000, Mansur encontrou dificuldade em manter o discurso do partido após o fracasso da gestão Pitta em São Paulo, apesar de ir para a disputa eleitoral com uma administração bem avaliada principalmente devido à pavimentação de diversas ruas e avenidas e às obras em toda a extensão da orla da praia e nos diversos atrativos turísticos. Após costurar amplo leque de alianças, conseguiu estabelecer apoio entre seu grupo político e o PMDB do ex-prefeito Oswaldo Justo. A aliança trouxe como vice-prefeito o seu ex-secretário de Meio Ambiente e ex-diretor presidente da Companhia de Engenharia de Tráfego (CET), João Paulo Tavares Papa. No segundo turno novamente contra o PT, o candidato do PPB foi reeleito após garantir a não declaração de apoio do PSDB a nenhum dos concorrentes, garantindo o isolamento da deputada federal Telma de Souza e a unificação da oposição, vencendo novamente por uma pequena diferença.

\section{0 projeto Alegra Centro: gestão, marketing e convencimento}

Na segunda administração Beto Mansur (20012004), a Secretaria de Planejamento (Seplan), comandada pelo vice-prefeito, ficou encarregada da elaboração e implantação de um programa específico de revitalização da área central. Desse modo, a prefeitura passou a contar com um arranjo institucional que teve como uma de suas atribuiç̧ões exclusivas coordenar um plano de recuperação da região, passando a desenvolver novos programas de intervenção e a se debruçar sobre um projeto de lei complementar que teria por objetivo dar apoio à implantação e ao funcionamento de atividades e empreendimentos através de iniciativas voltadas ao comércio e ao turismo, integrando todas as ações relativas a incentivos fiscais por meio de parcerias com a iniciativa privada (A Tribuna, 2001b).

0 texto de criação do projeto foi desenvolvido ao longo de 2001, e os incentivos foram dimensionados pela Secretaria de Economia e Finanças (Sefin) de modo a não prejudicar a arrecadação. Segundo projeção da própria secretaria, "de cada real oferecido em isenção, espera-se que sejam gerados três reais, numa relação que terá um impacto extremamente positivo nos futuros orçamentos" (Decreto, 2000). Segundo o então titular da Setur, Luiz Dias Guimarães: "Nós queremos beneficiar 100 empresários se possível. Nessa hora, é importante o convencimento. A ideia é formar um shopping center a céu aberto. Creio que em dois anos o Centro Histórico terá essa realidade" (A Tribuna, 2001a).

$\mathrm{Na}$ fase de discussões envolvendo a revitalização, o veículo de comunicação de maior apoio ao projeto foi o jornal local $A$ Tribuna com diversas notícias e reportagens. A matéria de janeiro de 2002, "Revitalização resgata economia do Centro e atrai novos investimentos", publicada no Caderno Economia, trouxe extensa reportagem relatando uma série de ações realizadas pelo poder público no intuito de mostrar a viabilidade do projeto e atrair empresários. Conforme a reportagem, empresas nacionais e internacionais demonstraram interesse pelo Centro pela sua proximidade com o cais e já procuravam imóveis para suas instalações. A publicação destacava ainda as recuperações do trecho 
entre a prefeitura e o calçadão da XV de Novembro, e de prédios antigos, atraindo empresas que estavam se fixando no local como bancos, lojas e escritórios de advocacia, entre outras empresas, como a sede da Construtora Phoenix, do ex-presidente da Associação dos Empresários da Construção Civil da Baixada Santista (Assecob), Omar Laino. Destaque também foi dado à questão da segurança com a instalação do $6^{\circ}$ Batalhão da Polícia Militar na reformada Praça dos Andradas com 130 homens e 15 viaturas. Por fim, a reportagem salientou que após as reformas das praças Mauá, Rui Barbosa e dos Andradas:

Esses espaços, antes degradados, perderam 0 aspecto de abandono e os desocupados se afastaram para outras áreas. Agora, a Praça Mauá é palco de eventos culturais. É de lá que parte o bonde, com uma linha ainda pequena, mas com papel importante para alavancar o turismo histórico no Centro. (A Tribuna, 2002, p. C3, grifo nosso)

Figura 2 - Rua XV de Novembro após as intervenções (Alegra Centro, 2013)

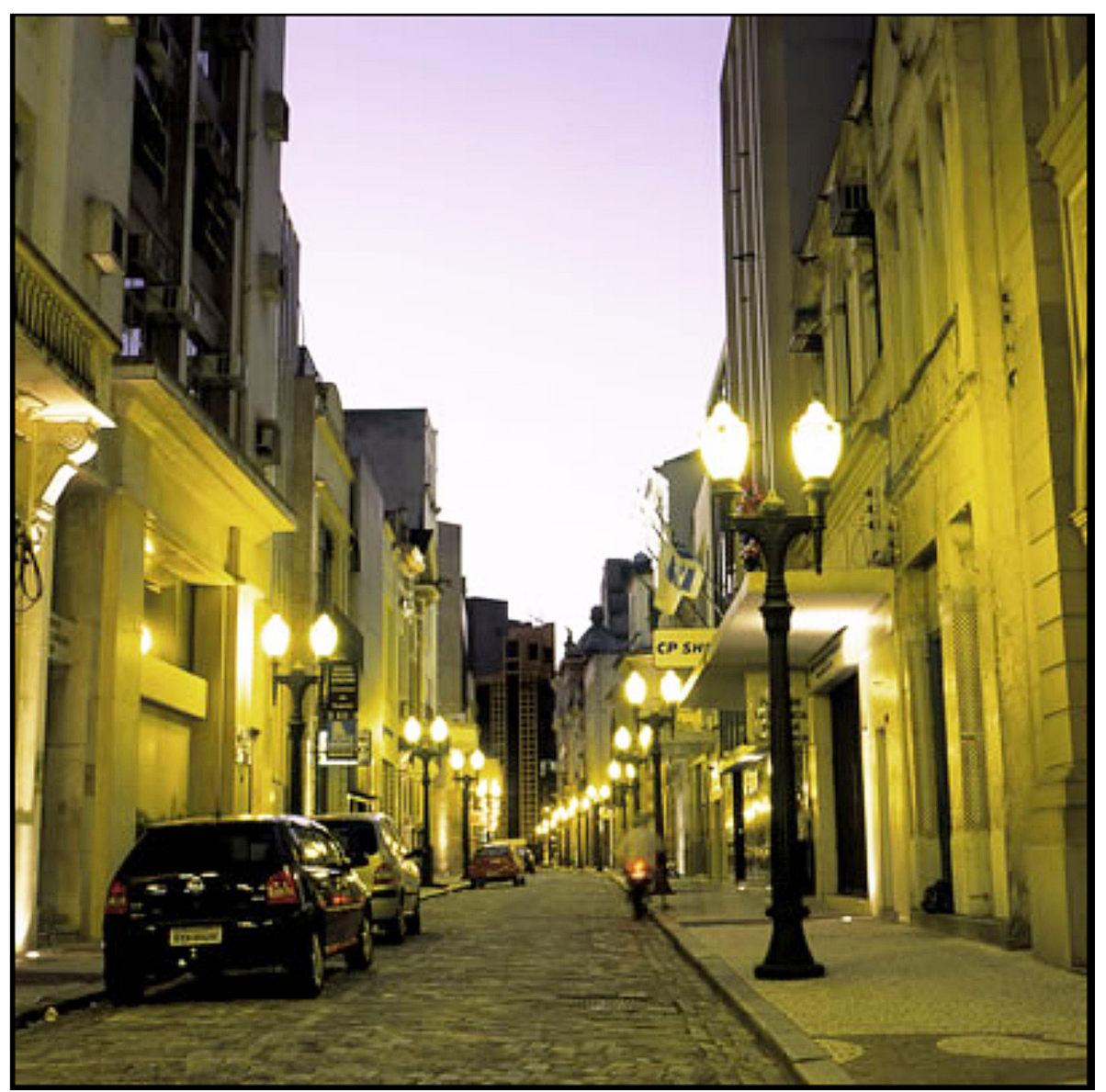


Dessa forma, através da lei complementar 470/03, foi criado o Programa de Revitalização e Desenvolvimento da Região Central Histórica de Santos, denominado Alegra Centro, dispondo sobre os elementos que compõem a paisagem urbana no local, fixando normas, padrões e incentivos fiscais. Estabelecido em consonância com a lei de uso e ocupação do solo, o programa teve como abrangência os imóveis localizados nas APC que integraram a Zona Central I, a Zona Central II e a Zona Portuária entre os armazéns 1 ao 8 enquadrados em um dos quatro Níveis de Proteção (NP):

I - Nível de Proteção 1 (NP 1) - Proteção total, atinge imóveis a serem preservados integralmente, toda a edificação, os seus elementos construtivos e decorativos, interna e externamente;

II - Nível de Proteção 2 (NP 2) - Proteção parcial, atinge os imóveis a serem preservados parcialmente, incluindo apenas as fachadas, a volumetria e o telhado;

III - Nível de Proteção 3 (NP 3) - Livre opção de projeto, mantendo-se, porém, a tipologia predominante dos imóveis NP1 e NP2 existentes na testada da quadra;

IV - Nível de Proteção 4 (NP 4) - Livre opção de projeto, respeitados os índices urbanísticos da zona em que o imóvel se encontrar, conforme a Lei Complementar $n^{\circ} 312 / 98$ e suas alterações (PMS, 2003).

Imediatamente após a sanção do projeto, foi dado início ao funcionamento do site do Alegra Centro reunindo informações referentes aos imóveis que poderiam receber empresas, os incentivos fiscais oferecidos, bem como as áreas contempladas, os endereços dos imóveis e banco de dados estatístico. Em conjunto tiveram início diversos eventos e ações de marketing junto a instituições representativas da sociedade civil como universidades, imprensa e associações. 0 Santos e Região Convention \& Visitors Bureau (SRCVB), criado em 2002, já vinha desempenhando amplo papel de divulgação. Tendo seu quadro executivo formado por entidades de classe, representantes do poder público e iniciativa privada, constituiu-se num grupo que integrou diversos segmentos econômicos e procurou propagar a região como destino para turismo de negócios e lazer, apoiando a realização de eventos e procurando incrementar as redes hoteleira e gastronômica.

Os participantes estabeleceram sede na rua XV de Novembro e ofereceram ampla sustentação de marketing à revitalização, contando com empresas de diversos setores como grupos de comunicação, universidades particulares e empresas na área de eventos. Tiveram participações destacadas no empreendimento o grupo $A$ Tribuna em diversas matérias televisivas e impressas, a Universidade Santa Cecília na realização de debates e seminários e a consultoria de comunicação do empresário Luiz Dias Guimarães, ex-secretário de Turismo da primeira gestão Mansur. A propagação do marketing alcançou, inclusive, a capital com reportagens veiculadas em jornais como Folha de S.Paulo, Valor Econômico e revistas como Veja SP e Exame (A Tribuna, 2002; D.O., 2003; Folha de S.Paulo, 2002; Valor Econômico, 2003).

Vargas (1998) e Vaz e Jacques (2003) analisaram com muita propriedade essa forma de marketing urbano frequentemente de responsabilidade do setor público, de forma conjunta ou isolada com a iniciativa privada, cujo objetivo é a criação de uma identidade local para o munícipe e a venda do lugar para os turistas: 
Tanto a cultura quanto a cidade passaram a ser consideradas como mercadorias, ou até mesmo, manipuladas como imagens de marca, principalmente dentro do atual processo de globalização da economia. (...), a cultura passa a ser concebida como uma "cultura-econômica", produzida com o intuito de ser vendida e consumida rapidamente. Com relação às cidades, 0 que ocorre não é muito diferente: a competição no interior de uma rede mundial é acirrada, as municipalidades se empenham para melhor vender a imagem de marca da sua cidade, muitas vezes em detrimento das necessidades da própria população local ao privilegiar o turismo, e neste sentido, favorecer a gentrificação de áreas a serem revitalizadas, principalmente aquelas centrais e ditas históricas. No momento em que as políticas urbanas passam a colaborar com as políticas culturais, a intenção das propostas permanece a mesma: com a finalidade de revitalizar a cidade através da cultura, o que se vê hoje é, na maioria dos casos, o que poderíamos chamar de "gentrificação cultural", ou seja, um enobrecimento, ou emburguesamento das atividades culturais urbanas através da criação de equipamentos midiáticos, porém elitistas. Mesmo quando são gratuitas, na maior partes dos casos estes são arquiteturas monumentais, intimidadoras, construídas nas partes centrais ou mais ricas das cidades para um público das classes mais abastadas e expondo basicamente arte erudita, na maior parte das vezes sem uma programação educacional competente para os leigos. (Vaz e Jacques, 2003, p. 132)

Ao final da gestão, as principais intervenções e projetos públicos desenvolvidos ou em desenvolvimento foram a implantação da linha de bonde percorrendo 1,7 km em pontos de interesse turístico-cultural e a instalação da unidade municipal "Incubadora de Empresas". A prefeitura terminou ainda as reformas das ruas Tuiuty, do Comércio e XV de Novembro e das praças Mauá, Rui Barbosa e dos Andradas e, em parceria com o governo do estado, implantou o "Banco do Povo Paulista", além de dar prosseguimento à reforma e restauração do Teatro Coliseu (A Tribuna, 2002; 2003).

Uma última medida legislativa da administração em relação ao Centro derivou ainda na ampliação, por decreto, do número de imóveis inseridos nas APC que até aquele momento havia produzido poucos resultados práticos, beneficiando apenas quatro imóveis. Fato esse que confirmou o diagnóstico da administração municipal de que era necessário maior investimento na divulgação e convencimento dos promotores imobiliários. A quantidade de imóveis que passaram a ter direito às isenções foi elevada de 686 para 1795, representando um aumento de aproximadamente 160\% ( $A$ Tribuna, 2004).

Em suma, as duas administrações Mansur, em especial a segunda, podem ser consideradas como gestões técnico-pragmáticas no sentido proposto por Frey (1996) como um estilo de governo municipal que colocou maior ênfase na modernização da máquina pública e num planejamento técnico eficiente, em que a participação da população no diagnóstico de suas necessidades, ou na definição das prioridades políticas, foi muito restrita ou inexistente. Nesse sentido, as gestões foram politicamente tranquilas, não enfrentando, nem no establishment local, nem na população em geral, um clima contrário aos projetos do governo. 
Ademais, a administração soube aproveitar-se de um eficiente marketing do lugar onde a condição de ser único foi enfatizada como estratégia para enfrentar a competição entre as cidades transformando-a num produto de consumo (Vargas, 1998; Vaz e Jacques, 2003). As duas - na avaliação da maioria da população - boas gestões, contribuíram para fortalecer a imagem de um governo competente e engenhoso. Estabeleceu-se, desse modo, uma confiança geral na atuação da administração e uma espécie de "voto de confiança" por parte da população que possibilitou ao governo, além de fazer o sucessor, realizar outros projetos e programas, sem estar obrigado a negociar esses empreendimentos com a sociedade civil. Com essa estratégia, a gestão Mansur conseguiu realizar projetos importantes, sem que, porém, essas inovações tivessem fugido ao controle da elite local ou contrariassem seus interesses primordiais.

\section{Para quem se destina a revitalização?}

Com o segundo turno disputado entre PT e PMDB, o vice-prefeito da gestão anterior João Paulo Tavares Papa foi eleito com 50,37\% dos votos válidos, superando pela terceira vez por uma pequena diferença $(49,63 \%)$ a mesma candidata petista das duas últimas eleições contando como fatores decisivos para a vitória no segundo turno o apoio do PSDB e do governador, Geraldo Alckmin (Seade, 2013). A gestão Papa (2005-2008) representou, sobretudo, uma continuidade político-administrativa no tocante às políticas públicas e aos principais projetos já delineados. Isso valeu, sobretudo, para a política de desenvolvimento urbano na qual a atenção do governo se voltou mais intensamente para o Centro e para a imagem da cidade como principais bandeiras da gestão.

Observou-se, nesse sentido, a preocupação com a apresentação, o mais rápido possível, de resultados concretos para ganhar o apoio da população dividida pelas eleições. Exemplo disso foi a modificação, ainda nos primeiros meses de governo, de dispositivos do programa Alegra Centro a fim de conter críticas e atender reivindicações que já vinham desde o final da administração Mansur de uma parcela dos empresários por melhores resultados. As alterações procuraram flexibilizar algumas exigências do programa no intuito de impulsionar sua efetividade, pois em pouco mais de três anos de funcionamento havia concedido apenas 65 benefícios de isenção fiscal entre ITBI, IPTU, ISS, além de taxas de licença (A Tribuna, 2005b).

Da mesma forma, a administração apressou-se em negociar a retirada do projeto de lei enviado por Mansur à Câmara de regulamentação do Estatuto da Cidade e o anúncio de "uma bateria de discussões e debates para elaborar uma nova legislação de planejamento urbano de Santos" (A Tribuna, 2005a, p. A3). 0 texto, reformulado por técnicos da Seplan, resultou na lei complementar 551/05 que disciplinou a utilização de instrumentos de política urbana preconizados pelo Estatuto e fixou as condições para sua implantação podendo ser aplicados em qualquer área do município. Com as alterações os casarões que se encontravam fechados, abandonados ou subutilizados passariam a poder arcar com o IPTU Progressivo no Tempo ou o parcelamento e a edificação 
compulsória caso os proprietários não dessem uma finalidade social à construção ou ao vazio urbano no prazo fixado pela notificação ( $A$ Tribuna, 2005c).

No entanto, em análise crítica posterior, Rios (2011) salientou que esses instrumentos praticamente não foram acionados. De acordo com a autora, pela não prioridade da administração em uma política fundiária e habitacional, mecanismos urbanísticos como as Operações Urbanas Consorciadas permaneceram sem utilização, assim como a Outorga Onerosa do Direito de Construir que mostrou resultados sem relevância e a Transferência do Direito de Construir que nunca foi solicitada. Além desses, os Estudos Prévios de Impacto Ambiental (EIA) e os Estudos Prévios de Impacto de Vizinhança (EIV) não foram regulamentados, impedindo sua utilização.

Em simultâneo, ações e projetos mostrados com grande divulgação dos órgãos oficiais e na imprensa local foram executados, como a transferência para a área central das secretarias de Turismo e Educação, procurando transformar esses locais em pontos de maior atração e circulação, e o início da recuperação do Teatro Guarany e da Casa do Trem com recursos de patrocinadores privados e investimentos obtidos pela Lei Rouanet. A conclusão das reformas do Pantheon dos Andradas e da demorada restauração do Teatro Coliseu - após mais de uma década de impasses burocráticos envolvendo a prefeitura e o governo do estado - iniciou um período de maior estreitamento entre as duas esferas de governo. 0 bom relacionamento das administrações municipal e estadual, que já vinha desde a gestão anterior, teve papel de destaque no repasse de verbas e em parcerias como na instalação do restaurante popular
"Bom Prato" na área do Mercado, o início da reforma nos antigos armazéns da Companhia de Entrepostos e Armazéns Gerais do estado de São Paulo (Ceagesp) para criação de um posto do programa de prestação de serviços públicos "Poupatempo", assim como a ampliação da linha turística do bonde, passando de 1,7 para 5 km de extensão percorrendo 32 pontos de interesse cultural, e na cessão das ruínas dos Casarões do Valongo para instalação do "Memorial José Bonifácio"4 (D.O., 2006a; 2006b; 2006c).

No plano cultural, diversos eventos buscaram maximizar as potencialidades locais como a "Caminhada histórica pelo Centro de Santos" em parceria com o grupo A Tribuna, percorrendo quatro quilômetros com início e fim na Praça Mauá, e o "Carnabonde" tocando marchinhas e abrindo o carnaval santista. Da mesma forma, foram incentivados outros acontecimentos simbólicos e festivos dando ênfase a espetáculos e exposições na tentativa de atrair frequentadores também para o período noturno. Exemplos disso foram a instituição da marca turística oficial inspirada no bonde e no Centro histórico, a maratona cultural "Caros Amigos", a ampliação do projeto "Música na XV" de apresentação de grupos musicais iniciado na gestão Mansur, a inauguração de um espaço cultural na Casa da Frontaria Azulejada, a "Virada Cultural" promovida pelo governo do estado e atrações como desfiles de moda, mostras de museus, apresentações teatrais e lançamentos de livros (D.O., 2006a) reforçando a imagem analisada por Vaz e Jacques (2003) de um "renascimento urbano, principalmente das áreas centrais" na qual "a cultura vem se destacando como estratégia principal e a ênfase das políticas urbanas recai sobre as políticas culturais" (p. 132). 
De todas essas ações, que demonstram o empenho e a prioridade do poder público na região central, pode-se constatar que o processo de revitalização tem conseguido importantes conquistas em termos de legislação, intervenções, reformas e projetos. Entretanto, esses ganhos têm sido exatamente para quem? 0 entendimento de que o Centro tem avançado de forma positiva pode ser estendido para a população residente da área, moradora principalmente de cortiços e habitações precárias? Podemos supor que ela foi igualmente beneficiada?

Infelizmente, com relação à população moradora local, o período tem sido marcado pela ineficácia e ineficiência no que se refere às questões sociais, notadamente as relacionadas à inclusão social, emprego e habitação. Conforme já analisado em trabalho anterior (Santos, 2011), e demonstrado na comparação entre os censos 2000 e 2010, esse tipo de habitação - que conta com aproximadamente 14 mil pessoas (3,5\% da população) - não viu melhoria em suas condições de vida. Além dos dados do IBGE, o Índice Paulista de Vulnerabilidade Social (IPVS) da Fundação Seade atestam a imobilidade socioeconômica da quase totalidade dos moradores dessa região que permanece com alguns dos maiores índices de vulnerabilidade alta (urbanos) e muito alta (aglomerados subnormais urbanos) (IBGE, 2010; Seade, 2000; 2010).

Ou seja, não houve alteração na situação em que as pessoas da região continuam vivendo em moradias coletivas improvisadas e em casarões abandonados com iluminação e ventilação precárias e onde são frequentes casos de tuberculose. Nessas edificações é bastante alto o grau de degradação física (goteiras, infiltrações e mofo nas paredes) e superlotação. Os cômodos são espaços restritos, multifuncionais, insalubres, sem higiene nem conforto. Os banheiros, cozinha e tanque são de uso comum com pouca privacidade, e os moradores não têm contrato formal de moradia com o locatário (os quartos são sublocados), assim como não há proteção da legislação. Em relação à questão social, segundo Martin et al. (2011, p. 695):

Os moradores, além de possuírem baixa escolaridade, poderiam ser considerados socialmente desviantes, como: ex-presidiários, trabalhadores do sexo, pessoas que viviam de trabalhos autônomos e "bicos", de pequenos furtos e de doações de cestas básicas. Alguns faziam uso frequente de substâncias psicoativas ilícitas e abuso do álcool. Apesar da alta rotatividade de pessoas, era comum encontrar a "dona da chave" (pessoa que explicitamente liderava e organizava o cortiço).

No entanto, dificuldades técnicas, financeiras e políticas foram, nos últimos anos, as principais razões alegadas pelos governos que impediram a execução das propostas de solução do problema de moradia para os encortiçados, sobretudo nas regiões do Mercado e Paquetá, as que mais sofrem com a falta de uma política efetiva de promoção da inclusão (Santos, 2011). Exemplo disso é o fato de que, após o término do prazo de seis anos estipulado para conclusão, nenhum dos quatro empreendimentos do Programa de Atuação em Cortiços (PAC) do governo do Estado havia sido entregue ( $A$ Tribuna, 2006a). 
Em junho de 2006, a situação era do primeiro empreendimento parado por conta do rompimento do contrato com a construtora na rua João Pessoa devendo ser retomado no mês seguinte, segundo o gerente regional da Companhia de Desenvolvimento Habitacional e Urbano (CDHU), o ex-presidente da Assecob José Marcelo Ferreira Marques. Outros dois, na rua Amador Bueno, sequer haviam saído do papel: um projeto estava em fase de análise, e a outra construção já estava licitada, mas a área ainda deveria ser desocupada. Apenas o quarto empreendimento, na rua São Francisco, estava - com bastante atraso - sendo executado. De acordo com relatório geral do programa de atuação em cortiços, após doze anos do programa, em maio de 2012, apenas 113 unidades habitacionais haviam sido entregues pela CDHU no município, uma média de menos de 10 unidades por ano (CDHU, 2012).

Em posicionamento crítico, Carriço (2006) afirmou que o período fez uso de propostas totalmente descoladas da realidade local em benefício de propostas de interesse restrito a determinados setores da sociedade que, certamente, não eram os mais necessitados da ação estatal. Segundo o autor, no caso específico dos projetos para a área central, "evidencia-se a ausência de propostas que visem enfrentar as dinâmicas socioeconômicas que vêm contribuindo, há décadas, para a transformação daquele espaço, processo equivocadamente compreendido como 'esvaziamento', 'degradação' ou 'decadência' do centro" (p. 413).

As eleições municipais confirmaram 0 favoritismo que as pesquisas atribuíam à reeleição do candidato Papa para o período 20092012, vencida pela primeira vez em um único turno desde a instituição de dois turnos em âmbito municipal. Com $77 \%$ dos votos válidos, o candidato do PMDB agregou em torno de si dezessete partidos e procurou dar maior ênfase às questões sociais, notadamente saúde e habitação popular, os pontos mais criticados da sua gestão.

Conforme previsto no Estatuto das Cidades, a revisão do plano diretor iniciado em 2009 resultou nas leis complementares 729/11 de Ordenamento do Uso e Ocupação da Área Continental, na lei referente ao Uso e Ocupação da Área Insular (n. 730/11) e o novo Plano Diretor de Desenvolvimento e Expansão Urbana, instituído pela legislação 731/11. Vaz e Vazquez (2011) apontaram nos planos aprovados a falta de propostas concretas e compromisso com metas quantificadas no sentido de terem as ações acompanhadas ao longo do tempo a partir de indicadores e prazos estabelecidos, correndo o risco de se tornarem apenas uma "carta de intenções" no sentido sustentado por Villaça (2005). De forma similar, ressaltaram a não inclusão de mais um dos chamados vetores de desenvolvimento, o vetor inclusão social, defendido por entidades da sociedade civil organizada.

Em contrapartida, não houve na lei de uso e ocupação modificações significativas nos índices urbanísticos tais como limitação da altura das edificações, coeficiente de aproveitamento máximo, taxa de ocupação máxima e recuos mínimos, além de outros. Essa não alteração, de acordo com Rios (2011), manteve e aprofundou o modelo excludente de supervalorização imobiliária. Exemplo bastante significativo desse fenômeno é o fato de o município não conseguir oferecer nenhuma opção de imóveis voltados às classes baixa e média que se encaixem no programa Minha Casa, Minha 
Vida (MCMV), do governo federal, que visa ampliar a oferta de financiamento para moradias destinadas a famílias com renda de 0 a 10 salários mínimos (A Tribuna, 2010).

\section{Considerações finais}

As duas administrações do PPB (atual PP) de 1997-2000 e 2001-2004 representaram, sobretudo por razões políticas em relação aos governos anteriores e em consonância com o ideário típico dos anos 1990, o início de uma visão que reforçou já em suas competências termos de cunho neoliberal como "gerenciar", "parcerias com os agentes econômicos", " captação de recursos", " planejamento estratégico", "administração gerencial", "atrair investimentos". Essas gestões tiveram, de maneira geral, uma relação de maior proximidade com os grupos sociais ligados à produção imobiliária e com os demais setores privados. Para tanto, foi fundamental a estratégia de convencimento e legitimação perante a sociedade fundamentada ideologicamente em um intenso e eficiente marketing em torno da promoção da cidade e da identidade local.

De modo geral, os governos João Paulo Tavares Papa (2005-2008 e 2009-2012) do PMDB foram de continuidade política, o que pode ser comprovado na insignificante utilização dos instrumentos urbanísticos sociais presentes no Estatuto das Cidades e pelo resultado das discussões em torno da revisão do plano diretor e das leis de uso e ocupação, em 2011, que não alteraram as características gerais de incentivo à verticalização, ao adensamento e à supervalorização imobiliária (Santos, 2012).
No sentido proposto por Smith (2006), a política urbana santista dos últimos anos demonstrou uma evolução do processo de gentrificação que emergiu de uma anomalia local para uma estratégia urbana articulada, compreendida através de características interligadas como "o novo papel do Estado; a penetração do capital; a dispersão geográfica; e a generalização da gentrificação setorial" (p. 75). Ainda baseado no autor, é possível identificar a instauração do posicionamento pró-mercado nas gestões Mansur e Papa e o novo papel do poder público no decorrer do processo, tendo sua significativa atuação nos anos 1990 definida pela clara parceria de capitais privados e políticas locais. Houve também o que pode ser chamado de capital globalizado, proveniente de fontes de investimentos diversificadas e que se configuraram como fator marcante da gentrificação. A vinda de grandes construtoras e incorporadoras imobiliárias e empreendimentos de luxo voltado às classes altas nos últimos anos atestam essa tendência.

No que se refere em específico ao processo de revitalização na área central, também foi percebida a significativa elitização da região, percebida agora como alternativa cultural e de entretenimento das classes média e alta. Ainda apoiado em Smith (2006), a regeneração urbana surgiu "como representante de uma estratégia central na competição global entre as diferentes aglomerações urbanas" (p. 85) e sobressai nesses processos o cuidado sobre a questão da escala de atuação dos projetos. Nesse sentido, é igualmente perceptível a ineficácia das administrações no tocante à inclusão dos moradores dos cortiços, principalmente nas demandas relativas à habitação e inclusão social que permaneceram sem alterações 
relevantes em todo o período analisado e não encontraram a mesma prioridade política nem a mesma eficiência administrativa de outras áreas do governo.

Sob essa perspectiva, apesar do processo de revitalização da área central ser um projeto inacabado e que ainda está em curso, podemos dizer que essas administrações produziram um conjunto de estímulos e incentivos às atividades econômicas privadas que não levou em conta uma proposta efetiva que integrasse socialmente os moradores locais. Ademais, sabemos que muitas das ações e projetos relacionados à região central estão ocorrendo em simultâneo à realização desta pesquisa e, dessa forma, temos ciência de que nossa contribuição - em uma perspectiva de processo - tem um caráter transitório, podendo, inclusive, ser revertido. Desse modo, vemos a necessidade de a política urbana santista ser revista pelo poder público e pela sociedade civil organizada nos próximos anos, de modo que possa ser olhada de forma mais crítica, participativa e inclusiva, especialmente com relação à população local mais pobre, tão cidadã e detentora do direito à cidade quanto 0 restante da população.

\section{André da Rocha Santos}

Observatório das Metrópoles, Núcleo Baixada Santista. Santos/SP, Brasil. andrerochasantos@gmail.com

\section{Notas}

(1) O programa nunca foi executado, pois, segundo a administração, dificuldades técnicas, financeiras e políticas impediram que a proposta fosse implantada (Carvalho, 1999).

(2) A Transferência do Potencial Construtivo ou Transferência do Direito de Construir é um instrumento de incentivo à preservação e consiste na compensação pela não utilização do coeficiente de aproveitamento permitido na respectiva zona de uso. A área a ser objeto é igual à diferença entre a área máxima de construção permitida para o imóvel e a área efetivamente construída (PMS, 1998b).

(3) A chamada verba Dade na verdade vinha do Fundo de Melhoria das Estâncias e vinculava-se ao Departamento de Apoio ao Desenvolvimento das Estâncias instituído em 1992. O Fundesb fez parte do arranjo institucional que estruturou a Região Metropolitana da Baixada Santista (RMBS) junto ao Conselho de Desenvolvimento da Região Metropolitana da Baixada Santista (Condesb) e da Agência Metropolitana da Baixada Santista (Agem), instituídos em 1996.

(4) Posteriormente o projeto do Memorial José Bonifácio foi substituído para abrigar o Museu Pelé. 


\section{Referências}

ALEGRA CENTRO (2013). Disponível em: http://www.alegracentro.com.br. Vários acessos.

ALMEIDA, L. C. (2004). PPB: origem e trajetória de um partido de direita no Brasil. Dissertação de mestrado. São Paulo, Universidade de São Paulo.

ARANTES, O. (2000). "Uma estratégia fatal: a cultura nas novas gestões urbanas". In: ARANTES, O.; MARICATO, E. e VAINER, C. B. A cidade do pensamento único: desmanchando consensos. Petrópolis, Vozes.

A TRIBUNA (2001a). “Programa será formalizado em 30 dias”. Santos, 25 jul 2001.

(2001b). “Revitalização: Escritório Técnico poderá mudar realidade do Centro”. Santos, 21 out 2001.

(2002). "Revitalização resgata economia do Centro e atrai novos investimentos". Santos, 13 jan 2002.

(2003). “Obras no Centro já somam R\$ 24 mi”. Santos, 27 nov 2003.

(2004). “Alegra Centro tem áreas de proteção cultural alteradas". Santos, 29 maio 2004.

(2005a). "Para duas décadas: prefeitura vai iniciar debates para mudar as regras urbanísticas da cidade, levando em conta a opinião de todos os segmentos da sociedade". Santos, 6 fev 2005.

(2005b). “Alegra Centro é mudado para ter novos parceiros”. Santos, 23 mar 2005.

(2005c). “Mudança de postura: legislação deverá ser colocada em prática na cidade em 2006 com instrumentos polêmicos, como o IPTU progressivo sobre os imóveis subutilizados". Santos, 30 maio 2005.

(2006a). “Moradores de cortiços buscam financiamento para projetos”. Santos, 21 jun 2006.

(2006b). “Erradicação de cortiços continua atrasada”. Santos, 11 jul 2006.

(2006c). “Obras serão finalizadas entre maio e novembro de 2007”. Santos, 7 dez 2006.

(2010). "Santos tem poucos imóveis voltados às classes baixa e média”. Santos, 13 jul 2010.

BOTELHO, (2005). T. R. Revitalização de centros urbanos no Brasil: uma análise comparativa das experiências de Vitória, Fortaleza e São Luís. Revista Eure. Santiago do Chile, v. XXXI, n. 93.

CARRIÇO, J. M. (2006). Baixada Santista: transformações produtivas e socioespaciais na crise do capitalismo após a década de 1980. Tese de doutorado. São Paulo, Universidade de São Paulo.

CARVALHO, S, N. (1999). Planejamento urbano e democracia: a experiência de Santos. Tese de doutorado. Campinas, Universidade Estadual de Campinas.

CASTELLS, M. (1982). A intervenção administrativa nos grandes centros urbanos. Espaço e Debates. São Paulo, n. 6.

COMPANHIA DE DESENVOLVIMENTO HABITACIONAL E URBANO (CDHU). (2012). Relatório geral do programa de atuação em cortiços CDHU-PAC. Secretaria da Habitação, Governo de São Paulo, maio. 
DECRETO (2000). Valoriza patrimônio histórico. A Tribuna. Santos, 1ํ jun.

DIÁRIO OFICIAL DE SANTOS. (1996). “Ações da Prefeitura revitalizam o Centro”. Santos, 4 abr.

(2003). Lei Municipal Complementar n. 470, de 5 de fevereiro: Cria o programa de revitalização e desenvolvimento da região central e histórica de Santos - Alegra Centro. Santos/SP, 6 fev.

(2006a). “Centro se consolida como polo de desenvolvimento". Santos, 15 ago.

(2006b). “Governo do estado cede área dos Casarões do Valongo à Prefeitura”. Santos, 1 set. (2006c). “Ampliação da linha do Bonde já está em frente ao Coliseu”. Santos, 6 dez.

FOLHA DE S.PAULO (2002). "Santos resgata boemia para revitalizar o Centro”. São Paulo, 25 dez.

FREY, K. (1996). "Crise do estado e estilos de gestão municipal”. Lua Nova: Revista de cultura e política. São Paulo, Centro de Estudos de Cultura Contemporânea, n. 37.

FRÚGOLI JUNIOR, H. (2000). Centralidade em São Paulo: trajetórias, conflitos e negociações na metrópole. São Paulo, Cortez/Edusp.

FUNDAÇÃO SISTEMA ESTADUAL DE ANÁLISE DE DADOS (SEADE). (2013). Disponível em: http://www. seade.gov.br/. Acesso em: 20 ago 2013.

GONÇALVES, A. (2009). Plano Diretor: planejamento e legislação urbana. Revista da Procuradoria Geral do Município de Santos. Santos/SP, Centro de Estudos da Procuradoria Geral do Município de Santos, ano V, n. 6.

HARVEY, D. (1992). Condição pós-moderna. São Paulo, Edições Loyola.

IANNI, O. (2004). Estado e capitalismo. São Paulo, Brasiliense.

IBGE (2010). Informações sobre os municípios brasileiros. Disponível em: http://cidades.ibge.gov. br/xtras/perfil.php?lang=\&codmun=354850\&search=| | infogr\%E1ficos:-informa\%E7\%F5escompletas. Acesso em: 23 abr 2014.

MAINWARING, S.; MENEGUELLO, R. e POWER, T. (2000). Partidos conservadores no Brasil contemporâneo: quais são, o que defendem, quais são suas bases. São Paulo, Paz e Terra.

MARTIN, D.; ANDREOLI, S. B.; PINTO, R. M. F. e BARREIRA, T. M. H. M. (2011). Condições de vida de portadores de transtornos psicóticos vivendo em cortiços em Santos. Revista de Saúde Pública, v. 45, n. 4 , pp. 693-699.

NOBRE, E. A. C. (2003). Intervenções urbanas em Salvador: turismo e gentrificação no processo de renovação urbana do Pelourinho. In: X ENCONTRO NACIONAL DA ANPUR. Anais. Belo Horizonte, Anpur.

NUNES, L. A. de P. (2005). A construção da esfera pública no planejamento urbano. Uma perspectiva histórica, Santos: 1945-2000. Tese de doutorado. São Paulo, Universidade de São Paulo.

PIERUCCI, A. F. e LIMA, M. C. (1991). A direita que flutua: o voto conservador na eleição de 1990 em São Paulo. Novos Estudos Cebrap. São Paulo, n. 29.

(1993). São Paulo 92, a vitória da direita. Novos Estudos Cebrap. São Paulo, n. 35. 
PREFEITURA MUNICIPAL DE SANTOS (PMS). (1998a). Lei Municipal Complementar n. 311 de 24 de novembro de 1998: Institui o plano diretor de desenvolvimento e expansão urbana do município de Santos e dá outras providências. Diário Oficial de Santos. Santos/SP, 25 nov.

(1998b). Lei Municipal Complementar $n^{\circ} 312$, de 24 de novembro de 1998: Disciplina o ordenamento do uso e ocupação do solo na área insular do município de Santos e dá outras providências. Diário Oficial de Santos. Santos, 25 nov.

(2003). Plano de revitalização da região central histórica de Santos. Santos/SP, Prefeitura Municipal de Santos

RIOS, L. G. (2011). “O processo de revisão do Plano Diretor de Santos à luz das diretrizes do Estatuto das Cidades”. In: VAZQUEZ, D. A. (org.). A questão urbana na Baixada Santista: políticas, vulnerabilidades e desafios para o desenvolvimento. São Paulo, Editora Universitária Leopoldianum.

SANTOS, A. R. (2011). Habitação precários e os cortiços da área central de Santos. Cadernos Metrópole. São Paulo, v. 13, n. 26, pp. 549-571.

(2012). Estado e política pública urbana: a revitalização do Centro de Santos. Tese de doutorado. Araraquara, Universidade Estadual Paulista “Júlio de Mesquita Filho".

SÃO PAULO (ESTADO). (2012). Relatório final do programa de atuação em cortiços CDHU-PAC. Secretaria de Estado da Habitação. Disponível em: http://www.cdhu.sp.gov. br/download/ manual/RelatorioGeralProgramaCorticos.pdf. Acesso em: 15 abr 2014.

SEADE (2000). Índice Paulista de Vulnerabilidade Social - IPVS. Disponível em: http://www.seade.gov. br/projetos/ipvs/mapas/Municipio/santos.pdf. Acesso em: 20 abr 2014.

(2010). Índice Paulista de Vulnerabilidade Social - IPVS. Disponível em: http://www.iprsipvs. seade.gov. br/view/index.php?prodCod=2\&selLoc=3548500\&selTpLoc=2\#. Acesso em: 23 abr 2014.

Disponível em: http://www.seade.gov.br/. Acesso em: 20 ago 2013.

SMITH, N. (2006). “A gentrificação generalizada: de uma anomalia local à 'regeneração' urbana como estratégia urbana global”. In: BIDOU-ZACHARIASEN, C. (org.). De volta à cidade: dos processos de gentrificação às políticas de revitalização dos centros urbanos. São Paulo, AnnaBlume.

(2007). Gentrificação, a fronteira e a reestruturação do espaço urbano. GEOUSP - Espaço e Tempo. São Paulo, n. 21, pp. 15-31.

SOUZA, C. D. C. (2006). Planejamento urbano e políticas públicas em projetos de requalificação de áreas portuárias: porto de Santos - desafio deste novo século. Dissertação de mestrado. São Paulo, Universidade de São Paulo.

VAINER, C. B. (2000). "Pátria, empresa e mercadoria. Notas sobre a estratégia discursiva do planejamento estratégico urbano". In: ARANTES, O.; MARICATO, E. e VAINER, C. B. A cidade do pensamento único: desmanchando consensos. Petrópolis, Vozes.

VALOR ECONÔMICO (2003). “Ação coordenada dá à velha Santos uma face moderna”. São Paulo, 11 jun. 
VARGAS, H. C. (1998). Turismo e valorização do lugar. Turismo em análise. São Paulo, Escola de Comunicação e Artes, v. 9, pp. 7-19.

VASCONCELLOS, L. M. e MELLO, M. C. F. de (2006). "Re: atrás de, depois de...". In: VARGAS, H. C. e CASTILHO, A. L. H. (orgs.). Intervenções em centros urbanos: objetivos, estratégias e resultados. Barueri, Manole.

VAZ, L. F. e JACQUES, P. L. (2003). A cultura na revitalização urbana: espetáculo ou participação? Espaço e Debates, v. 23, n. 43-44, pp. 129-140.

VAZ, J. O.; VAZQUEZ, D. A. (2011). "Da Santos que temos a Santos que queremos: um diagnóstico socioeconômico para subsidiar o processo de revisão do Plano Diretor". In: VAZQUEZ, D. A. (org.). A questão urbana na Baixada Santista: políticas, vulnerabilidades e desafios para o desenvolvimento. São Paulo, Editora Universitária Leopoldianum.

VILLAÇA, F. (2013). As ilusões do Plano Diretor. Disponível em: http://www.flaviovillaca.arq.br/pdf/ ilusao_pd.pdf. Acesso em: 21 jun 2013.

Texto recebido em 14/out/2013

Texto aprovado em 7/abr/2014 
